九州大学学術情報リポジトリ

Kyushu University Institutional Repository

\title{
High-efficiency yellow double-doped organic light-emitting devices based on phosphor- sensitized fluorescence
}

D' Andrade, Brian W.

Center for Photonics and Optoelectronic Materials (POEM), Department of Electrical Engineering and the Princeton Materials Institute, Princeton University | Department of Chemistry, University of Southern California

Baldo, Marc. A.

Center for Photonics and Optoelectronic Materials (POEM), Department of Electrical Engineering and the Princeton Materials Institute, Princeton University

Adachi, Chihaya

Center for Photonics and Optoelectronic Materials (POEM), Department of Electrical Engineering and the Princeton Materials Institute, Princeton University

Brooks, Jason

Department of Chemistry, University of Southern California

他

http://hdl. hand le. net/2324/19450

出版情報: Applied Physics Letters. 79 (7)，pp. 1045-1047，2001-08-13. American Institute of Physics

バージョン :

権利関係: Copyright 2001 American Institute of Physics. This article may be downloaded for personal use only. Any other use requires prior permission of the author and the American Institute of Physics. 


\title{
High-efficiency yellow double-doped organic light-emitting devices based on phosphor-sensitized fluorescence
}

\author{
Brian W. D'Andrade, Marc A. Baldo, Chihaya Adachi, Jason Brooks, ${ }^{\text {a) }}$ \\ Mark E. Thompson, ${ }^{\text {a) }}$ and Stephen R. Forrest ${ }^{\text {b) }}$ \\ Center for Photonics and Optoelectronic Materials (POEM), Department of Electrical Engineering \\ and the Princeton Materials Institute, Princeton University, Princeton, New Jersey 08544
}

(Received 14 March 2001; accepted for publication 31 May 2001)

\begin{abstract}
We demonstrate high-efficiency yellow organic light-emitting devices (OLEDs) employing [2-methyl-6-[2,3,6,7-tetrahydro-1H,5H-benzo[ij]quinolizin-9-yl)ethenyl]-4H-pyran-4-ylidene] propane-dinitrile (DCM2) as a fluorescent lumophore, with a green electrophosphorescent sensitizer, fac tris(2-phenylpyridine) iridium $\left[\operatorname{Ir}(p p y)_{3}\right]$ co-doped into a $4,4^{\prime}-N, N^{\prime}$ dicarbazole-biphenyl host. The devices exhibit peak external fluorescent quantum and power efficiencies of $9 \% \pm 1 \%(25 \mathrm{~cd} / \mathrm{A})$ and $17 \pm 2 \mathrm{~lm} / \mathrm{W}$ at $0.01 \mathrm{~mA} / \mathrm{cm}^{2}$, respectively. At $10 \mathrm{~mA} / \mathrm{cm}^{2}$, the efficiencies are $4.1 \% \pm 0.5 \%(11 \mathrm{~cd} / \mathrm{A})$ and $3.1 \pm 0.3 \mathrm{~lm} / \mathrm{W}$. We show that this exceptionally high performance for a fluorescent dye is due to the $\sim 100 \%$ efficient transfer of both singlet and triplet excited states in the doubly doped host to the fluorescent material using $\operatorname{Ir}(p p y)_{3}$ as a sensitizing agent. These results suggest that $100 \%$ internal quantum efficiency fluorescent OLEDs employing this sensitization process are within reach. (C) 2001 American Institute of Physics.
\end{abstract}

[DOI: $10.1063 / 1.1388159]$

Over the last two decades, advances in organic lightemitting device (OLED) efficiencies have been made through the synthesis of efficient lumophores, optimization of the OLED structure, and doping of OLEDs with highly emissive phosphorescent and fluorescent materials. ${ }^{1,3,4}$ In particular, the highest external quantum efficiencies ${ }^{4,5}\left(\eta_{\text {ext }}\right)$ of $\sim 18 \%$ reported thus far employ the electrophosphorescent molecule fac tris(2-phenylpyridine) iridium $\left[\operatorname{Ir}(p p y)_{3}\right]$ doped into hosts such as $4,4^{\prime}-N, N^{\prime}$-dicarbazole-biphenyl (CBP). The large $\eta_{\text {ext }}$ of these devices is attributed to emissive triplet excitons that set an upper limit to the internal quantum efficiency $\left(\eta_{\text {int }}\right)$ of $100 \%$. In contrast, given a statistical limit of 1:3 for the singlet-to-triplet exciton ratio in molecular organic materials, ${ }^{6}$ the maximum $\eta_{\text {ext }}$ for fluorescent materials is only $\sim 5 \%$, ultimately limited by the output coupling efficiency ${ }^{2,7}$ of $\sim 20 \%$ for OLEDs with flat glass substrates.

The recent demonstration of phosphor sensitization ${ }^{8}$ provides a means for fluorescent OLEDs to approach efficiencies similar to those of electrophosphorescent devices through resonant energy transfer between triplet excitons in the phosphor and singlets in the fluorophore. Phosphor sensitization works as follows: By doping a phosphor at high concentrations $(\sim 5-10 \mathrm{wt} \%)$ into a conductive host, both singlet and triplet excitons can transfer onto the phosphor molecule. If the phosphor contains a heavy metal atom, spinorbit coupling transfers all excited states on the phosphor to the radiative triplet manifold. These radiative states can then be readily transferred via the dipole-dipole Förster ${ }^{9}$ process to the radiative singlet state of the fluorophore co-doped with both the host and phosphor molecules. By lightly doping

\footnotetext{
${ }^{a)}$ Department of Chemistry, University of Southern California, Los Angeles, California 90089.

b)Electronic mail: forrest@princeton.edu
}

$(\sim 1 \%)$ the fluorophore, hopping from the host triplets to the nonradiative triplet state of the fluorescent molecule is discouraged. In principle, therefore, phosphor sensitization can lead to $100 \%$ internal quantum efficiency of OLEDs radiating from the singlet manifold of the fluorescent dopant molecules.

Here, we describe high-efficiency fluorescent OLEDs using a phosphorescent sensitizer. These OLEDs were improved and simplified from previous work ${ }^{8}$ by uniformly codoping the two dyes into the host material instead of using thin layers of the host alternately doped with the phosphorescent sensitizer and the fluorophore. At low current densities, we obtain a maximum external quantum efficiency of $9 \% \pm 1 \%$ (corresponding to an internal efficiency of $\sim 50 \%$ ) and a power efficiency of $17 \pm 2 \mathrm{~lm} / \mathrm{W}$ for fluorescent materials. Moreover, $\eta_{\mathrm{ext}}$ is found to be equal to that obtained in control devices containing only the phosphor, suggesting that the exciton transfer efficiency from phosphor to fluorophore is $\sim 100 \%$. This result indicates that phosphor-sensitized fluorescence provides a realistic route for obtaining $100 \%$ internal electroluminescence in fluorescent OLEDs.

As previously, ${ }^{8}$ the host material was CBP, and the dopants were $\operatorname{Ir}(p p y)_{3}$ and the yellow-red fluorescent dye $\mathrm{e}^{10}$ [2-methyl-6-[2,3,6,7 - tetrahydro-1H,5H-benzo[ij]quinolizin9-yl)ethenyl]-4H-pyran-4-ylidene]propane-dinitrile (DCM2). Organic layers were deposited by high-vacuum $\left(10^{-7}\right.$ Torr $)$ thermal evaporation onto a precleaned and uv-ozone ${ }^{11}$ treated glass substrate precoated with an indium-tin-oxide (ITO) anode having a sheet resistance of $\sim 20 \Omega /$ sq. A $40-$ nm-thick film of $N, N$-diphenyl- $N, N$-bis(3-methylphenyl)[1,1-biphenyl]-4, 4-diamine (TPD) served as the holetransport layer (HTL). Next, a 30-nm-thick light-emitting layer (EML) consisting of the CBP host was deposited while being simultaneously doped with $4-12 \mathrm{wt} \% \operatorname{Ir}(p p y)_{3}$, and $0.1-1.3 \mathrm{wt} \%$ DCM2 via thermal co-deposition from three 


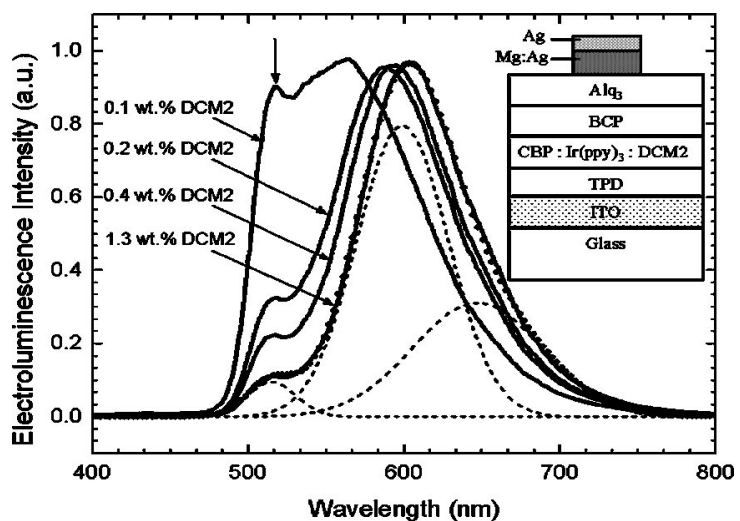

FIG. 1. Electroluminescence spectrum of devices doped with $0.1,0.2,0.4$, and $1.3 \%$ DCM 2 and 8 wt \% $\operatorname{Ir}(p p y)_{3}$ in CBP. The intensity of $\operatorname{Ir}(p p y)_{3}$ emission, indicated by the arrow, decreases, and the DCM2 peak emission redshifts with increasing DCM2 concentration. Gaussian fits of the spectral components of the device doped with $1.3 \mathrm{wt} \%$ DCM2 are shown as dashed lines. Inset: Schematic cross section of a phosphor-sensitized fluorescent OLED.

independent source boats. A 12-nm-thick layer of bathocuproine (BCP) was used to confine excitons ${ }^{12}$ in the EML. By trapping the excitons, their residence time and recombination probability in the EML were increased, leading to a concomitant increase in OLED efficiency. A 30-nm-thick layer of tris-(8-hydroxy-quinoline)aluminum $\left(\mathrm{Alq}_{3}\right)$ was used to transport and inject electrons into the EML. A shadow mask with 1-mm-diam openings was used to define the cathode consisting of a 100-nm-thick 10:1 layer with a 30-nm-thick silver cap. A schematic cross section of the device structure is shown in the inset of Fig. 1.

Electroluminescence (EL) was only observed from $\operatorname{Ir}(p p y)_{3}$ and DCM2 in all double-doped devices, indicating efficient transfer of excitons from the CBP host to the dopants, in addition to direct formation of excitons on $\operatorname{Ir}(p p y)_{3}$. Figure 1 (dashed lines) shows the emission of a device doped with 8 wt $\% \operatorname{Ir}(p p y)_{3}$ and $1.3 \mathrm{wt} \%$ DCM2, fit using three Gaussian curves by an iterative chi-square minimization routine with peaks at wavelengths of $\lambda=520,600$, and $650 \mathrm{~nm}$. The summation of all three Gaussians is shown by the dotted line overlapping the actual spectrum. From the ratio of the areas of the two DCM2 Gaussian spectral components to the total area under the curve, we can calculate the percentage of photons emitted from DCM2. Nearly 100\% DCM2 emission was observed with $1.3 \mathrm{wt} \% \mathrm{DCM} 2$, and $\sim 86 \%$ with a doping concentration of $0.1 \mathrm{wt} \%$ DCM2. Figure 1 also shows the reduction in the residual $\operatorname{Ir}(p p y)_{3}$ emission intensity (whose peak, indicated by the vertical arrow, is at $\lambda=520$ $\mathrm{nm}$ ) for devices doped with an increasing concentration of DCM2. Furthermore, a red spectral shift of the DCM2 peak from $\lambda=560 \mathrm{~nm}$ to $\lambda=600 \mathrm{~nm}$ is observed with increasing DCM2 concentration. Since DCM2 is a polar molecule, higher doping concentrations lead to a redshift in the emission $^{13}$ along with a substantial increase in aggregateinduced quenching, which lowers the quantum efficiency. There was no significant variation in the percentage of photons emitted by DCM2 between devices with different $\operatorname{Ir}(p p y)_{3}$ concentrations, provided that the DCM2 concentration was held fixed. This indicates efficient energy transfer

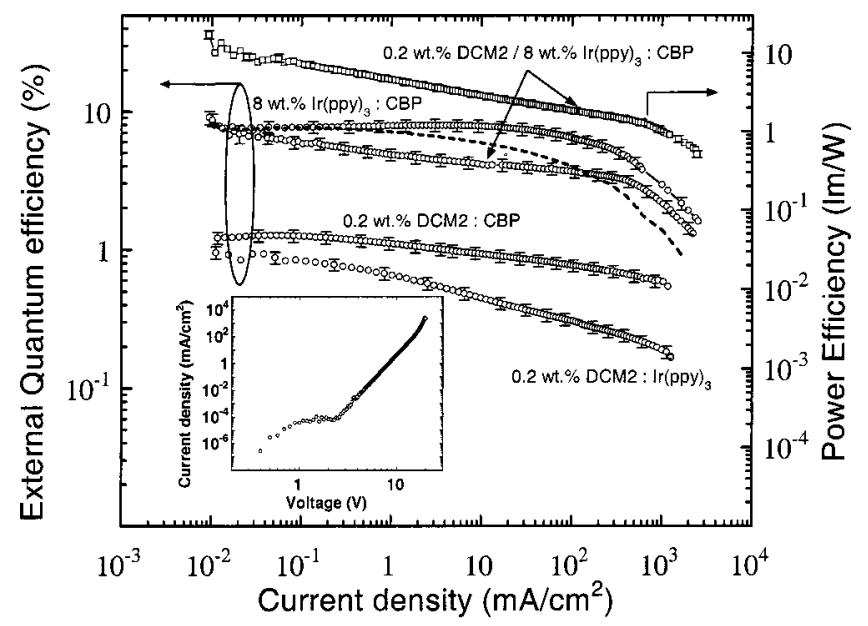

FIG. 2. External quantum and power efficiencies of single- and doubledoped OLEDs vs current density. A maximum external DCM2 quantum efficiency of $9 \pm 1 \%(25 \mathrm{~cd} / \mathrm{A})$ and power efficiency of $17 \pm 2 \mathrm{~lm} / \mathrm{W}$ are obtained for the $8 \mathrm{wt} \% \operatorname{Ir}(p p y)_{3} / 0.2$ wt $\%$ DCM2:CBP device. Dashed line shows the convolution between the 8 wt $\% \operatorname{Ir}(p p y)_{3}$ : CBP and the $0.2 \mathrm{wt} \%$ DCM2:CBP emission curves. Inset: Current-voltage characteristic of an 8 wt $\% \operatorname{Ir}(p p y)_{3} / 0.2$ wt \% DCM2:CBP device.

from $\operatorname{Ir}(p p y)_{3}$ to $\mathrm{DCM} 2$ at all concentration combinations employed.

The maximum DCM2 external quantum efficiency at low current densities $\left(J \leqslant 10^{-2} \mathrm{~mA} / \mathrm{cm}^{2}\right)$ was $\eta_{\text {ext }}=9 \pm 1 \%$ (25 cd/A) for an $8 \mathrm{wt} \% \operatorname{Ir}(p p y)_{3} / 0.2 \mathrm{wt} \%$ DCM2-doped device, corresponding to a maximum power efficiency of $\eta_{p}=17 \pm 2 \mathrm{~lm} / \mathrm{W}$ (see Fig. 2). The device had a luminance of $100 \mathrm{~cd} / \mathrm{m}^{2}$ at $8.3 \mathrm{~V}$ (corresponding to $\sim 1 \mathrm{~mA} / \mathrm{cm}^{2}$ ), calculated using current-voltage characteristics shown in the inset of Fig. 2. The variation in the hue was small over several orders of magnitude in current density, as inferred from the EL spectra shown in Fig. 3, inset. The value of $\eta_{\text {ext }}$ is double that of previously reported ${ }^{8}$ sensitized devices between current densities of 0.1 and $30 \mathrm{~mA} / \mathrm{cm}^{2}$, and nearly three times higher at current densities below $0.1 \mathrm{~mA} / \mathrm{cm}^{2}$, where $\eta_{\text {ext }}$ is comparable to a purely phosphorescent $\operatorname{Ir}(p p y)_{3}$ device, also shown in Fig. 2. This equivalence in maximum $\eta_{\text {ext }}$ for the

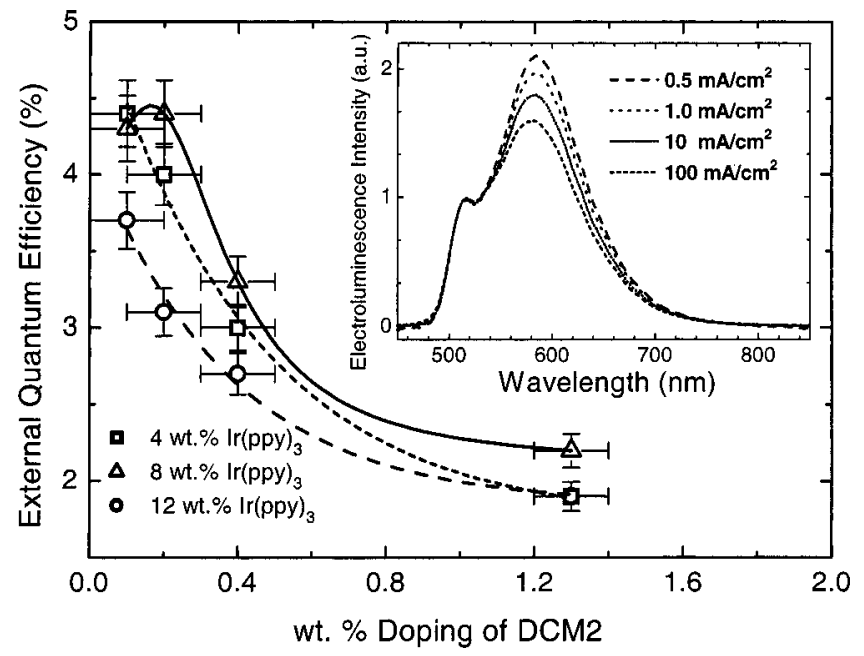

FIG. 3. External quantum efficiencies at $10 \mathrm{~mA} / \mathrm{cm}^{2}$ of devices co-doped with various concentrations of $\operatorname{Ir}(p p y)_{3}$ and DCM2. Inset: electroluminescent emission intensity as a function of wavelength for a 8 wt \% $\operatorname{Ir}(p p y)_{3} / 0.2$ wt \% DCM2 OLED at several current densities. DCM2 emission at $600 \mathrm{~nm}$ decreases from $96 \%$ at $0.5 \mathrm{~mA} / \mathrm{cm}^{2}$ to $93 \%$ at $100 \mathrm{~mA} / \mathrm{cm}^{2}$. 
TABLE I. Förster transfer radii and the internal photoluminescence efficiencies $\left(\eta^{0}\right)$ of the different molecules studied.

\begin{tabular}{lcc}
\hline \hline Material combination & Förster transfer radii/Å & $\eta^{0}$ \\
\hline CBP-DCM & $30 \pm 3$ & $0.53 \pm 0.05$ \\
CBP-Ir $(\text { ppy })_{3}$ & $29 \pm 3$ & $0.66 \pm 0.06$ \\
$\operatorname{Ir}(\text { ppy })_{3}-\mathrm{DCM} 2$ & $40 \pm 4$ & $0.66 \pm 0.06$ \\
\hline \hline
\end{tabular}

phosphor and the phosphor-sensitized fluorescent devices indicates that the exciton transfer efficiency between $\operatorname{Ir}(p p y)_{3}$ and DCM2 is $\sim 100 \%$. Given that only radiative triplet states produced by spin-orbit coupling on the $\operatorname{Ir}(p p y)_{3}$ molecule can transfer by Förster processes to DCM2, this suggests that the phosphor has successfully transferred all excited states from the host to the singlet manifold of the fluorescent dye.

A slow decrease in $\eta_{\text {ext }}$ between $0.01 \mathrm{~mA} / \mathrm{cm}^{2}$ at $4.7 \mathrm{~V}$ and $300 \mathrm{~mA} / \mathrm{cm}^{2}$ at $17 \mathrm{~V}$ is observed for all double-doped systems. It is also observed in the purely fluorescent DCM2:CBP OLED and the device using $\operatorname{Ir}(p p y)_{3}$ as the host doped with $0.2 \mathrm{wt} \%$ DCM2. Figure 2 shows that the decrease in $\eta_{\text {ext }}$ with current of the 0.2 wt $\%$ DCM2: $\operatorname{Ir}(\text { ppy })_{3}$ device is faster than that of the $0.2 \mathrm{wt} \%$ DCM2:CBP device, indicative of additional nonradiative energy pathways available between $\operatorname{Ir}(p p y)_{3}$ and DCM2, which are eliminated in the double-doped system. Furthermore, aggregate quenching of $\operatorname{Ir}(p p y)_{3}$ excitons substantially lowers the maximum $\eta_{\text {ext }}$ of the 0.2 wt $\%$ DCM2: $\operatorname{Ir}(\text { ppy })_{3}$ device to $<1 \%$.

Efficiencies of double-doped devices roll off sharply at $J \geqslant 300 \mathrm{~mA} / \mathrm{cm}^{2}$, similar to the 8 wt $\% \operatorname{Ir}(p p y)_{3}: \mathrm{CBP}$ device. This roll off is due to triplet-triplet $(T-T)$ annihilation ${ }^{14}$ between the $\operatorname{Ir}(p p y)_{3}$ and host triplets. The product of the efficiency of the $8 \mathrm{wt} \% \operatorname{Ir}(p p y)_{3}: \mathrm{CBP}$ and that from the $0.2 \mathrm{wt} \%$ DCM2:CBP devices results in the dashed curve shown in Fig. 2. The roll off in $\eta_{\text {ext }}$ at high currents of these structures precedes that in the double-doped device, indicating that $T-T$ annihilation in $\operatorname{Ir}(p p y)_{3}$ is reduced by the presence of the DCM2. This reduced annihilation is most probably due to rapid Förster transfer of the radiative $\operatorname{Ir}(p p y)_{3}$ triplet to the singlet manifold of DCM2. Hence, phosphor-sensitized fluorescence provides a mechanism for substantially reducing $T-T$ quenching. ${ }^{4,5}$

We attribute the exceptionally high efficiencies observed in DCM2 to the mixing of the two dopants with the host afforded by the co-deposition process. We can estimate the concentrations of dopants required to maximize $\eta_{\mathrm{ext}}$ by considering the Förster radii and hopping distances between different molecules in the EML layer. Hopping occurs between nearest-neighbor molecules that have separation distances of $\leqslant 5 \AA$ since intermolecular orbital overlap determines the transfer probability. In contrast, long-range Förster singletsinglet transfer radii and radiative triplet-singlet transfer radii extend over a considerably longer range. These radii have been calculated ${ }^{9}$ for the several material combinations employed, with the results provided in Table I.

Given the density of thin films of $\sim 1.3 \mathrm{~g} / \mathrm{cm}^{3}$, the weight ratio doping of the EML of $8 \mathrm{wt} \% \operatorname{Ir}(p p y)_{3} / 0.2 \mathrm{wt} \%$ DCM2 and the molecular masses of the organic materials, we find that each DCM2 molecule lies in a spherical volume of radius $38 \AA$, close to a calculated Förster radius of $40 \pm 4$ $\AA$. At $>1$ wt \% DCM2 doping, there should be little improvement in the transfer efficiency and a concomitant increase in the concentration quenching ${ }^{10}$ of DCM2 emission, consistent with the results in Fig. 3.

By independently varying concentrations of the dopants, we optimized the efficiency of $\operatorname{Ir}(p p y)_{3}$ and DCM2 OLEDs, with results shown in Fig. 3. The highest $\eta_{\text {ext }}$ of similarly doped DCM2 OLEDs were observed for devices containing 8 wt $\% \operatorname{Ir}(p p y)_{3}$. Hopping between CBP and $\operatorname{Ir}(p p y)_{3}$ is less likely at lower doping concentrations since fewer CBP molecules have $\operatorname{Ir}(p p y)_{3}$ as a nearest neighbor. At higher doping levels, concentration quenching of $\operatorname{Ir}(p p y)_{3}$ emission is dominant. ${ }^{6}$ Thus, we expect lower $\eta_{\text {ext }}$ for devices doped with 4 and $12 \mathrm{wt} \% \operatorname{Ir}(p p y)_{3}$, as observed. Also, there is a noticeable decrease in the efficiency of the devices as the concentration of DCM2 is increased due to concentration quenching of singlets transferred to that molecule.

In conclusion, we have demonstrated that co-doping of the conductive host molecule CBP with $<1 \mathrm{wt} \%$ DCM2 and an $\operatorname{Ir}(p p y)_{3}$ sensitizer considerably improves the external fluorescence quantum efficiency of OLEDs. Optimized devices exhibit $\eta_{\mathrm{ext}}=9 \pm 1 \%(25 \mathrm{~cd} / \mathrm{A})$ and $\eta_{p}=17 \pm 2 \mathrm{~lm} / \mathrm{W}$ at $0.01 \mathrm{~mA} / \mathrm{cm}^{2}$. The results show that Förster transfer between $\operatorname{Ir}(p p y)_{3}$ and DCM2 can be made $\sim 100 \%$ efficient leading to fluorescent OLEDs whose efficiency is equal to that of purely electrophosphorescent OLEDs. In addition, phosphorsensitized fluorescent OLEDs exhibit reduced $T-T$ annihilation as compared with purely phosphor-doped devices due to the rapid and efficient transfer of radiative triplet states to the singlet manifold of the fluorescent molecular dopant.

The authors thank the Universal Display Corporation, the Defense Advanced Research Projects Agency, and the National Science Foundation's Materials Research Science and Engineering Center for their support.

${ }^{1}$ C. W. Tang and S. A. VanSlyke, Appl. Phys. Lett. 51, 913 (1987).

${ }^{2}$ V. Bulovic, V. B. Khalfin, G. Gu, and P. E. Burrows, Phys. Rev. B 58, 3730 (1998).

${ }^{3}$ M. A. Baldo, D. F. O’Brien, Y. You, A. Shoustikov, S. Sibley, M. E. Thompson, and S. R. Thompson, Nature (London) 395, 151 (1998).

${ }^{4}$ M. A. Baldo, S. Lamansky, P. E. Burrows, M. E. Thompson, and S. R. Forrest, Appl. Phys. Lett. 75, 4 (1999).

${ }^{5}$ C. Adachi, M. A. Baldo, S. R. Forrest, and M. E. Thompson, Appl. Phys. Lett. 77, 904 (2000).

${ }^{6}$ M. A. Baldo, D. F. O'Brien, M. E. Thompson, and S. R. Forrest, Phys. Rev. B 60, 14422 (1999).

${ }^{7}$ G. Gu, D. Z. Garbuzov, P. E. Burrows, S. Venkatesh, S. R. Forrest, and M. E. Thompson, Opt. Lett. 22, 396 (1997).

${ }^{8}$ M. A. Baldo, M. E. Thompson, and S. R. Forrest, Nature (London) 403, 750 (2000).

${ }^{9}$ T. Förster, Discuss. Faraday Soc. 27, 7 (1959).

${ }^{10}$ C. W. Tang, S. A. VanSlyke, and C. H. Chen, J. Appl. Phys. 65, 3610 (1989).

${ }^{11}$ D. J. Milliron, I. G. Hill, C. Shen, A. Kahn, and J. Schwartz, J. Appl. Phys. 87, 572 (2000).

${ }^{12}$ D. F. O'Brien, M. A. Baldo, M. E. Thompson, and S. R. Forrest, Appl. Phys. Lett. 74, 442 (1999).

${ }^{13}$ V. Bulovic, A. Shoustikov, M. A. Baldo, E. Bose, V. G. Kozlov, M. E. Thomspon, and S. R. Forrest, Chem. Phys. Lett. 287, 455 (1998).

${ }^{14}$ M. A. Baldo, C. Adachi, and S. R. Forrest, Phys. Rev. B 62, 10967 (2000). 